\title{
К ВОПРОСУ ПРАКТИЧЕСКОГО ПРИМЕНЕНИЯ МЕТОДИКИ УСТАНОВЛЕНИЯ ПРИНАДЛЕЖНОСТИ ОБЬЕКТА К ОГНЕСТРЕЛЬНОМУ ОРУЖИЮ
}

\author{
E.A. Erakhtina
}

\section{TO THE QUESTION OF PRACTICAL APPLICATION OF THE TECHNIQUE FOR ESTABLISHING THE OBJ ECT'S BELONGING TO FIRE-ARMS WEAPONS}

Разработка и внедрение цифровых методов в судебнобаллистические исследования ставят перед криминалистами задачу выработки соответствующих современным условиям критериев оценки, используемой автоматизированной криминалистической техники. Необходимо учитывать, что в разработке и внедрении циифровъх методов автоматизированной криминалистической техники, позволяющих на высоком научно-техническом уровне решать задачи, которые стоят перед судебно-баллистической экспертизой (непременно при обязательном для данных случаев соблюдения принципов объективности и доказательственного значения), нуждается как следствие, так и суд. Важно отметить, что находясь сегодня на довольно высоком уровне развития, судебная баллистика имеет определенные трудности, обусловленные устаревшими теоретическими и методическими положениями данного рода исследований. Разработка теоретических и методических положений, адекватных современному уровню развития науки и техники, является одной из задач, стоящих перед экспертными органами. Злободневность актуализации методологии судебно-баллистических исследований связана с особенностями данного вида исследований, транснациональным характером преступности, технической оснащенностью преступников и их вооруженностью современными образцами стрелкового оружия. Кроме того, принимая во внимание факты противоправного распространения стрелкового оружия, появления его новъх видов, а также возросшее число преступлений, при совершении которых оно применяется, крайне сложно разработать актуальные практические рекомендации по криминалистической идентификации оружия. В статье рассмотрены методические, правовые (процессуальные), организационные проблемы криминалистического исследования нарезного огнестрельного оружия, в том числе вопросы принадлежности объекта к огнестрельному оружию, определения пригодности патронов для стрельбы при производстве баллистических экспертиз и исследований, при- 
чины экспертных ошибок при проведении идентификационных баллистических экспертиз.

Ключевъе слова: судебно-баллистические исследования, криминалистическая техника, стрелковое оружие, криминалистическая идентификация оружия, криминалистическое исследование, нарезное огнестрельное оружие, пригодность патронов для стрельбы, экспертные ошибки, баллистическая экспертиза.

The development and implementation of digital methods in forensic ballistic research pose the task of forensic investigators to develop the assessment criteria appropriate for modern conditions and automated forensic technology used. It should be borne in mind that in the development and implementation of digital methods of automated forensic technology, allowing at high scientific and technical level to solve the problems facing forensic ballistic examination (of course, if the principles of objectivity and evidentiary value are mandatory for these cases) need both investigation and court. It is important to note that, being at rather high level of development today; judicial ballistics has certain difficulties due to outdated theoretical and methodological provisions of this kind of the research. The development of theoretical and methodological provisions adequate to modern level of development of science and technology is one of the tasks facing expert bodies. The urgency of updating the methodology of forensic ballistic research is associated with the features of this type of the research, transnational nature of crime, technical equipment of criminals and their armament with modern small arms. Besides, taking into account the facts of unlawful proliferation of small arms, the emergence of new types of them, as well as increased number of crimes in the commission of which it is used it is extremely difficult to develop relevant practical recommendations for the forensic identification of weapons. In the study methodological, legal (procedural), organizational problems of forensic investigation of rifled firearms, including the issues of the object of their belonging to firearms, determining the suitability of cartridges for firing in the preparing ballistic examinations and the studies, the reasons for expert errors during identification ballistic examinations are considered.

Keywords: judicial ballistic research, forensic equipment, small arms, forensic identification of weapons; forensic investigation, cut firearms, the suitability of cartridges for shooting; expert errors, ballistic examination.

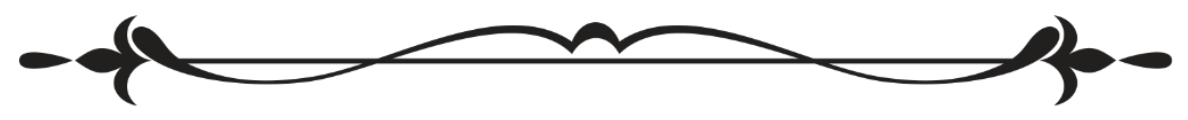

Количество регистрируемых преступлений, совершаемых с применением ручного стрелкового оружия, неуклонно растет. Особенно большую опасность представляет ежегодное пополнение оружия, находящегося в незаконном обороте. 


\section{Социально-экономический и әуманитарный журрнал Красноярского ГАУ. 2019. № 4}

Между тем противоправное распространение стрелкового оружия это одна из главных причин увеличения количества преступлений, совершаемых с его применением. Зачастую в преступных целях используется огнестрельное, значительно реже ствольное газовое и пневматическое оружие, однако практика показывает, что эти виды оружия довольно часто служат основой для изготовления огнестрельного (путем переделки, приспособления и т. п.).

Данные доводы находят свое подтверждение в статистических показателях. Так, в 2016 г. в Красноярском крае было выявлено 275 человек, совершивших преступления, связанные с незаконным оборотом оружия, вместе с тем уже в 2017 г. - 400 человек; в 2018 г. - тенденция сохранилась, но уже к сентябрю 2019 г. - 342 человека.

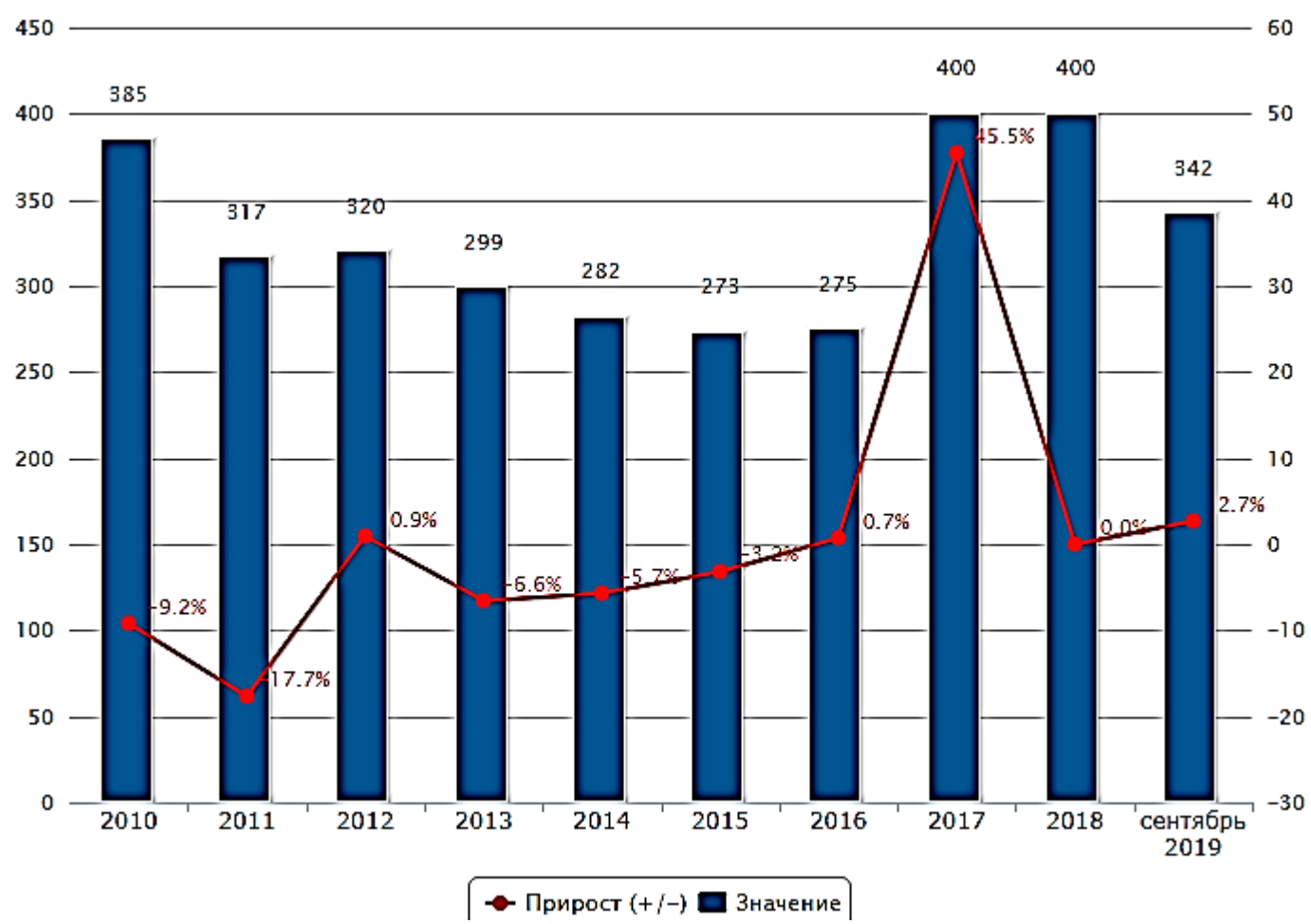

В то же время преступлений, связанных с незаконным оборотом оружия, в Красноярском крае в 2016 г. зарегистрировано 560, в 2017 г. 759; в 2018 г. - 719, но уже к сентябрю 2019 г. - 654 преступления.

Чрезвычайная опасность преступлений, совершаемых с применением огнестрельного оружия, требует особенно высокого качества расследования по этим делам, при котором необходимо использовать все возможности для установления преступников [1, с. 5].

Исследование фигурировавших при совершении преступлений всевозможных материальных объектов и их следов, в том числе: оружия и подобных ему изделий; боеприпасов; частей этих объектов, материалов и инструментов для их изготовления; следов применения, хранения, изготовления, переделки оружия и патронов, - помогает в значительной мере установить сущность и обстоятельства расследуемого преступления. 


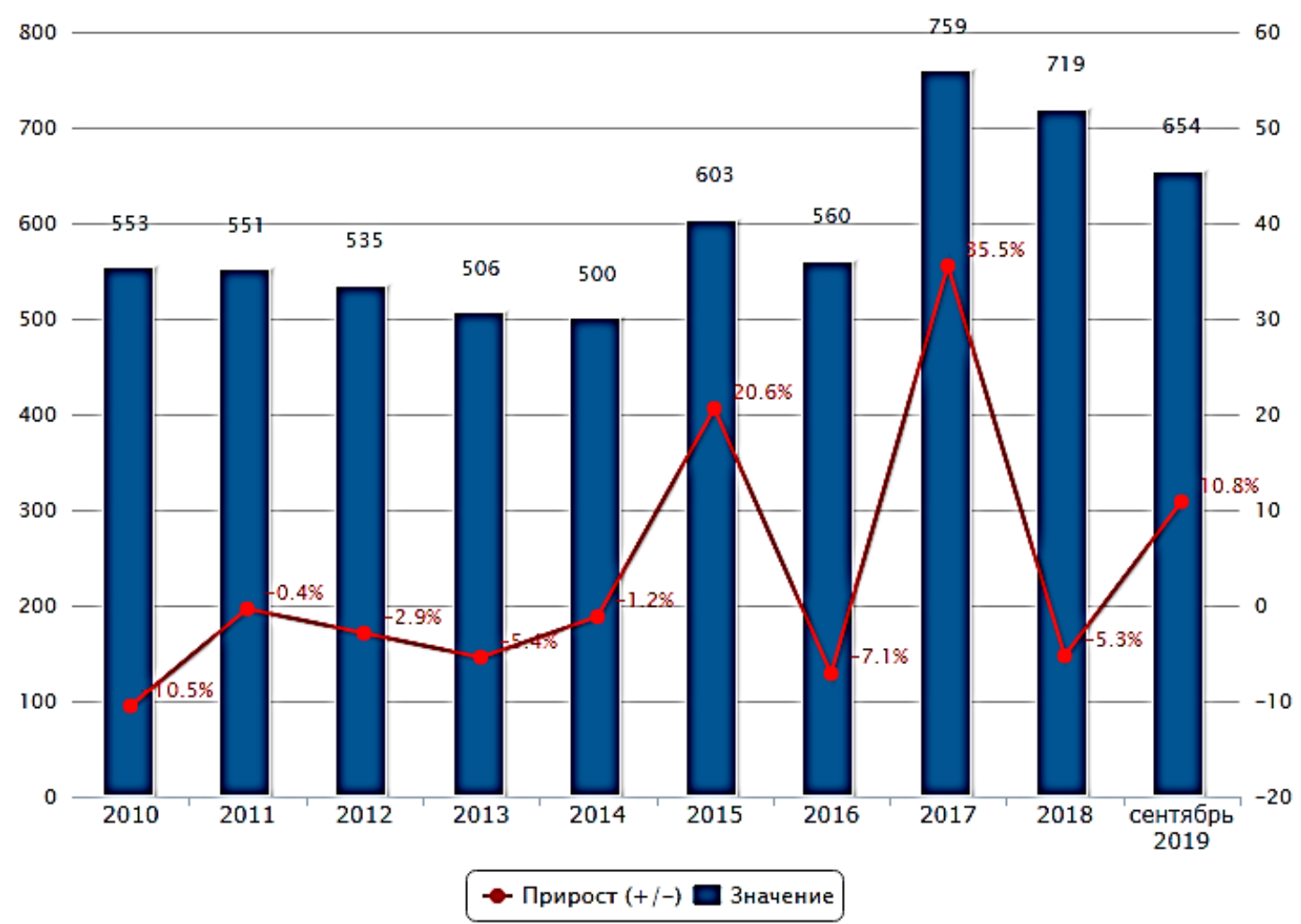

Однако при производстве баллистических исследований в настоящее время наибольшие затруднения у экспертов вызывают вопросы практического применения «Методики установления принадлежности объекта к огнестрельному оружию» (далее по тексту - методика) в части именно дифференциации признаков промышленного, переделанного и самодельного огнестрельного оружия.

Так, согласно примечанию к пункту 6.3 указанной выше методики, объекты промышленного производства с необратимыми изменениями конструкции, внесенными самодельным способом, или собранные из частей оружия разных моделей (в том числе и не прошедших полного цикла технологической обработки), а также самодельные объекты, в которых использованы детали, части и механизмы промышленного производства, должны классифицироваться и исследоваться в части, касающейся исследования самодельного огнестрельного оружия по пункту 6.9 данной методики [2. с. 2-3].

Вместе с тем следует иметь в виду, что умышленная степень внесенных самодельных изменений преступником в оружие промышленного производства может быть различной и в разной степени затрагивать конструкцию оружия и его баллистические свойства. По этим причинам данное обстоятельство следует учитывать при окончательной классификации исследуемого оружия по способу его изготовления. 


\section{Социально-экономический и әуманитарный журнал Красноярского ГАУ. 2019. № 4}

В то же время действующая методика не устанавливает точных критериев дифференциации оружия по способу изготовления в зависимости от степени внесенных изменений, поскольку границы или перечень указанных изменений, которыми можно было бы руководствоваться при принятии решения, установить фактически невозможно.

Анализ практики производства баллистических экспертиз свидетельствует о том, что при принятии решения экспертам целесообразно руководствоваться в первую очередь тем, в какой степени внесенные изменения затрагивают конструкцию оружия, его основные части и детали, непосредственно участвующие в производстве выстрела, а также баллистические свойства оружия. Существенным фактором также является то, в каком объеме в целом изменения внесены в конструкцию.

Так, если в оружие промышленного производства внесены незначительные самодельные изменения, которые не затрагивают или затрагивают в незначительной степени конструкцию основных частей и деталей, участвующих в производстве выстрела, не оказывают существенного влияния на баллистические свойства оружия или занимают незначительный объем по отношению ко всей конструкции в целом (даже при переделке или замене основных частей), то такое оружие в большинстве случаев целесообразно классифицировать как переделанное или неисправное оружие промышленного производства.

В качестве примеров можно привести обрез охотничьего ружья, стандартный револьвер с замененным стволом, боевой карабин с патронником, расточенным под другой тип патрона, охотничий карабин с удаленным блокиратором приклада, разобщителем, ограничителем патронов в магазине и т. п., автомат с удаленным прикладом, газовый револьвер с удаленной перегородкой в стволе и т. д.

Если же конструкция оружия полностью изготовлена самодельным способом, объем внесенных изменений в оружие промышленного производства по отношению ко всей конструкции в целом занимает большую часть либо конструкция собрана из частей оружия разных моделей, в том числе и самодельного оружия, то подобные объекты целесообразно классифицировать как полностью самодельное оружие либо как самодельное оружие, изготовленное (собранное) с использованием тех или иных частей оружия промышленного производства.

Следует также иметь в виду, что точная классификация оружия по способу изготовления и оценка его баллистических свойств не всегда напрямую связаны между собой. Так, если в оружие промышленного производства внесены несущественные изменения, не влияющие на его баллистические свойства и не меняющие конструкцию основных частей и деталей, участвующих в производстве выстрела, имеются все основания для отнесения данного объекта к категории оружия на основании 
его целевого назначения. В этом случае определение баллистических характеристик для решения вопроса о принадлежности объекта к оружию не требуется. Эксперт должен лишь отразить в заключении, какие изменения внесены, и решить вопросы об исправности оружия и пригодности его к стрельбе (если таковые поставлены на разрешение экспертизы).

В случае, если изменения внесены в основные части оружия (например, изготовлен или заменен ствол в газовом пистолете) и влияют на его баллистические характеристики или объект собран из частей оружия разных моделей, то для решения вопроса о принадлежности объекта к огнестрельному и иному оружию (даже если он будет классифицирован как промышленный образец, переделанный самодельным способом) необходимо определение его поражающих свойств в процессе экспериментальной стрельбы в соответствии с методикой исследования самодельного огнестрельного оружия.

Если из такого объекта можно произвести выстрел и удельная кинетическая энергия выстреленных из него снарядов равна или превышает

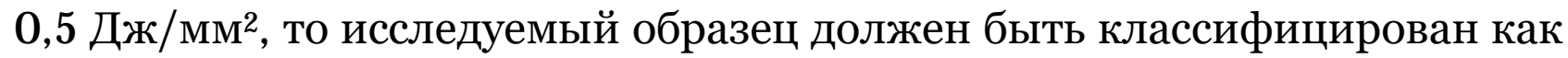
огнестрельное оружие с указанием особенностей его способа изготовления.

Следует также иметь в виду, что невозможно охватить все многообразие имеющихся и потенциально возможных конструкций переделанного и самодельного оружия, в связи с чем принятие обоснованного решения по рассмотренным вопросам при применении положений методики установления принадлежности объекта к огнестрельному оружию на практике в значительной степени зависит от опыта и квалификации эксперта-баллиста, который в каждом конкретном случае должен учитывать все особенности конструкции исследуемых образцов оружия, их баллистические характеристики и степень внесенных изменений.

Кроме того, в практике экспертов нередко встречается самодельное огнестрельное оружие, в конструкции которого отсутствует часть устройства для воспламенения метательного заряда. Подобные объекты не могут быть отнесены к огнестрельному оружию, поскольку в соответствии с пунктом 6.9.1. указанной методики из них нельзя произвести выстрел, не внося каких-либо изменений, затрагивающих материальную часть [2, с. 3]. На основании данного обстоятельства эксперт имеет все основания сформулировать отрицательный вывод и прекратить дальнейшее исследование.

Вместе с тем, учитывая, что в большинстве случаев дефекты устройств воспламенения метательного заряда являются несущественными и заключаются, как правило, в поломке бойка или отсутствии ударника, для оценки баллистических свойств объекта эксперт имеет право в по- 


\section{Социально-экономический и әуманитарный журнал Красноярского ГАУ. 2019. №4}

рядке эксперимента добавить в его конструкцию недостающий ударник (боек) или подходящий по конструкции металлический стержень, который способен выполнить функцию бойка ударника и обеспечить воспламенение капсюльного состава патрона.

В этом случае эксперт может провести дополнительное исследование по пункту 6.9. методики [2, С. 3-4]. Если из такого объекта можно произвести выстрел и удельная кинетическая энергия выстреливаемых

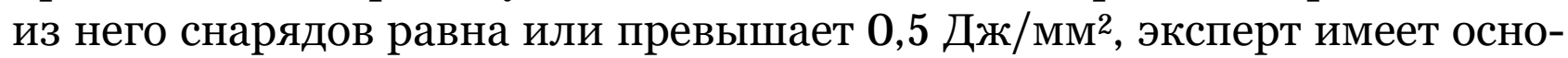
вания дополнительно указать в выводах, что при соблюдении условий эксперимента представленный объект обладает комплексом признаков огнестрельного оружия (необходимыми конструктивными элементами и достаточной поражающей силой).

Результаты проведенных исследований в значительной степени будут способствовать более объективной оценке следователем и судом общественной опасности совершенного преступления, а также оценке реальной возможности причинения опасных для жизни и смертельных повреждений с использованием данного оружия в конкретных условиях и при наличии конкретных обстоятельств совершения преступления.

Кроме того, пули и гильзы, полученные в процессе экспериментальной стрельбы, могут быть использованы для проведения идентификационных баллистических экспертиз, проверок по региональным и федеральным баллистическим учетам в целях расследования и раскрытия других преступлений.

Не менее важно затронуть проблему отсутствия единого понимания понятия «боеприпасы» в следственной, судебной и экспертной практике последних лет и как результат - неоднозначное понимание производства исследования боеприпасов в части решения вопроса о пригодности для стрельбы.

В соответствии с частью 6 статьи 11 Федерального закона от 31.05.2001 № 73-Ф3 «О государственной судебно-экспертной деятельности в Российской Федерации» государственные судебно-экспертные учреждения одного и того же профиля должны осуществлять деятельность по организации и производству судебной экспертизы на основе единого научно-методического подхода к экспертной практике, профессиональной подготовке и специализации экспертов.

В новой типовой методике экспертного решения вопроса о пригодности патронов для стрельбы от 17.02.2017 заложено обязательное определение поражающего действия снарядов всех патронов, в том числе и у патронов, изготовленных заводским способом. В соответствии с требованиями пункта 11 указанной методики при отстреле патронов промышленного и самодельного изготовления, предназначенных для поражения цели, необходимо определить поражающее действие снарядов. 
Согласно пункту 84.6.6 приказа МВД России от 11.01.2009 № 7 «Об утверждении Наставления по организации экспертно-криминалистической деятельности в системе МВД России», назначение баллистических экспертиз и исследований сотрудниками предварительного следствия и дознания региональных отделов ОВД для решения вопроса о пригодности патронов для стрельбы может быть организовано только в те экспертно-криминалистические подразделения, которые обеспечены приборами измерения скорости полета снаряда.

Соответственно, при отсутствии вышеуказанных сертифицированных технических средств баллистическую экспертизу (исследование) по вопросам отнесения патронов к категории боеприпасов можно провести в экспертно-криминалистических подразделениях районного уровня, а для решения вопроса о пригодности патронов к стрельбе - в ближайшем экспертно-криминалистическом подразделении, где имеется необходимое оборудование.

Нельзя также не отметить, что в Уголовном кодексе Российской Федерации, Постановлении Пленума Верховного суда от 12.03.2002 № 5 «О судебной практике по делам о хищении, вымогательстве и незаконном обороте оружия, боеприпасов, взрывчатых веществ и взрывных устройств» и других нормативно-правовых актах, регламентирующих решение вопросов при применении законодательства, предусматривающего ответственность за незаконное ношение, хранение, приобретение, изготовление или сбыт боеприпасов, а также за их хищение или вымогательство уголовная ответственность предусмотрена независимо от их пригодности или непригодности для производства выстрелов, однако судебная практика применения вышеуказанного законодательства неоднозначна.

Не менее важно остановиться на экспертных ошибках и их причинах при проведении идентификационных баллистических экспертиз.

Как точно сказал в свое время Р.С. Белкин: «Доказательственное значение экспертного заключения зависит от его истинности, внутренней непротиворечивости, точности и достоверности всех действий, оценок и выводов эксперта в ходе и по результатам процесса экспертного исследования. Экспертное заключение должно быть безошибочным, что требует своевременного распознавания предупреждения экспертных ошибок, а в конечном счете - искоренения причин, их порождающих» $[7$, c. 470$]$.

По мнению Е.Р. Россинской, экспертные ошибки - это суждение эксперта или его действия, которые не соответствуют объективной действительности и не приводят к цели экспертного исследования [8, с. 3].

Ею была предложена следующая классификация экспертных ошибок $[8$, c. 4]: 


\section{Социально-экономический и әуманитарный журнал Красноярского ГАУ. 2019. № 4}

\section{Виды экспертных ошибок}

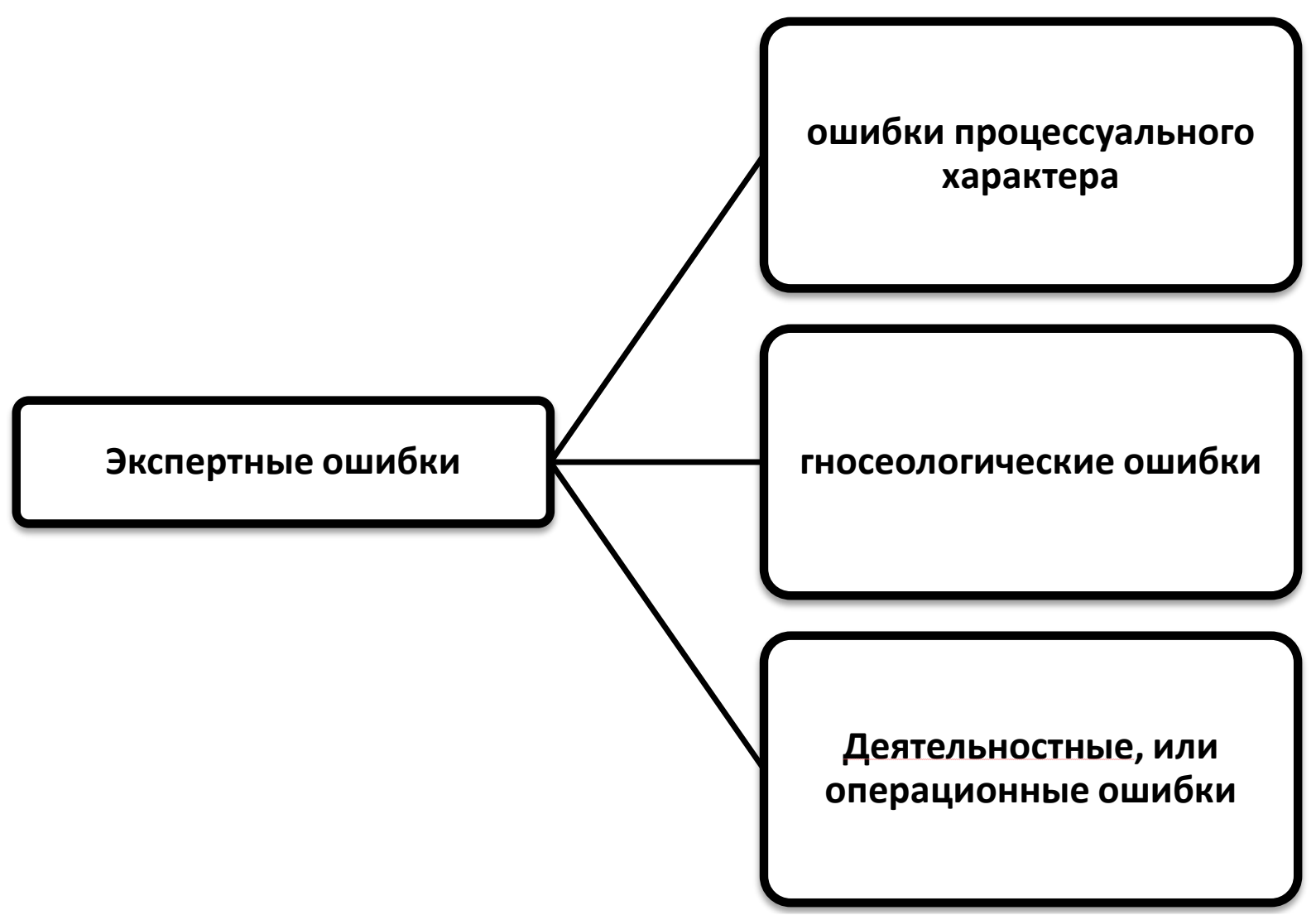

Причины экспертных ошибок, в свою очередь, можно классифицировать на объективные и субъективные. Объективными причинами являются недостаточная материально-техническая база экспертного подразделения и отсутствие необходимых условий для выполнения поставленных задач, нерациональная организация экспертного процесса, недостаточная справочно-информационная база об оружии и боеприпасах (патронах); видоизменение первоначальных свойств и характеристик объектов исследования и др. Эти ошибки не зависят от эксперта.

Субъективными причинами являются неисполнение или ненадлежащее исполнение экспертом процессуальных норм и должностных обязанностей, недостаточная профессиональная квалификация эксперта, неправильное применение рекомендуемых методик или несоблюдение этапов исследования объектов и следов на них, неправильная оценка идентификационной значимости признаков, неполнота исследования, эксперт небрежено и поверхностно провел исследования и др.

Основным требованием применения экспертных методик при производстве идентификационных баллистических экспертиз является строгое и последовательное соблюдение всех этапов исследования объектов и их полнота, а также формулирование выводов на основании всего комплекса выявленных признаков. Отступление от подобного ал- 
горитма действий эксперта влечет за собой не только необоснованные выводы, но и, как следствие, экспертные ошибки.

При установлении вида и образца патрона, частью которого является выстреленная пуля (стреляная гильза), наиболее распространенной причиной ошибок является неполное описание объектов исследования либо игнорирование отдельных признаков.

Например, при описании пули или фрагмента ее оболочки необходимо учитывать не только габаритные размеры и материал изготовления, массу, форму сохранившихся участков, толщину оболочки, но и способ крепления пули с гильзой. Так, пули с закругленной головной частью 7,62 мм патронов к пистолету ТТ, имеющие трехточечное кернение, также использовались при снаряжении патронов к 7,62-мм револьверу системы Нагана образца 1895 г., но имели двухточечное кернение. Игнорирование данного фактора в ряде случаев на практике привело к экспертным ошибкам.

Следующей причиной ошибочных выводов при проведении идентификационных экспертиз является неверное определение типа, вида, системы, модели и образца оружия, в котором стреляна гильза или из которого выстрелена пуля.

На данном этапе исследования необходимо выявить и описать весь комплекс следов от частей используемого оружия. При описании следов на гильзе необходимо учитывать не только следы от бойка, патронного упора, отражателя и зацепа выбрасывателя, их расположение и взаиморасположение, но и дополнительные следы от окна для выхода бойка, загибов магазина, пера колодки УСМ, ребра окна затвора и др.

При описании следов на пулях следует указать наличие или отсутствие нарезов, количество, направление, ширину и угол наклона полей нарезов, степень изношенности канала ствола, а также наличие следов газоотводного отверстия в канале ствола, глушителя при его несоосном расположении и т. п.

Если эксперт дает вывод о том, что пули выстрелены из самодельного ствола, то при описании следов необходимо указать конкретные признаки, указывающие на этот факт. Например, об этом свидетельствуют различная ширина следов полей нарезов, большой угол наклона вторичных следов, характер следов от боевых или холостых граней в виде глубокой канавки и др.

Нельзя до проведения идентификационного исследования утверждать, что исследуемые гильзы или пули выстрелены из конкретной модели (образца) оружия. По общим признакам системы оружия можно лишь определить предполагаемую модель оружия (например, гильзы могли быть стреляны в пистолете ПМ или другой модели оружия, 


\section{Социально-экономический и гуманитарнъцй журнал Красноярского ГАУ. 2019. № 4}

имеющей аналогичные форму, размеры и взаиморасположение следообразующих деталей конструкции).

Имеются случаи безосновательного признания объектов (пуля, дробь, картечь) непригодными для идентификации. Решение данного вопроса в категорически-отрицательной форме возможно лишь при предоставлении конкретного экземпляра оружия либо при отсутствии следов от канала ствола.

Так, например, эксперт при исследовании пули охотничьего патрона 12 калибра принял грубые следы от заусенцев дульного среза гладкоствольного обреза ружья за следы от контакта пули с твердой преградой и сформулировал ошибочный вывод о непригодности исследуемой пули для идентификации конкретного экземпляра оружия. В дальнейшем при предоставлении обреза данная пуля была идентифицирована и установлено тождество.

Важным этапом перед проведением сравнительных исследований является экспериментальная стрельба с целью получения следов частей и деталей оружия на стреляных гильзах и выстреленных пулях. Патроны должны максимально соответствовать патрону (патронам), использованному на месте происшествия, как по материалу изготовления гильзы и капсюля-воспламенителя, так и по времени изготовления, стране, заводу (фирме)-изготовителю.

Например, при стрельбе из 7,62 мм пистолета ТТ патронами разных производителей характер следов на гильзах и пулях имеет высокую степень вариационности, и в некоторых случаях установить тождество практически невозможно.

Следующей причиной ошибочных выводов при проведении идентификационных исследований является установление тождества по одной отдельной группе следов (например, по следам на гильзах от патронного упора или кончика бойка), без установления источника их происхождения.

Следует отметить, что в настоящее время при производстве стрелкового оружия используется современное высокоточное оборудование, режущие поверхности инструментов и производственных процессов которого отображаются на поверхностях деталей оружия в виде особенностей рельефа. Инструменты в процессе обработки поверхностей могут оставлять повторяющиеся следы как на деталях одного экземпляра оружия, так и на деталях разных экземпляров (рис. 1).

Дефекты в литейных формах также могут отображаться на различных деталях оружия и проявляться в их следах как признаки (рис. 2).

На кончиках бойков хорошо видны отобразившиеся дефекты поверхности литейной формы (рис. 3,4$)$. 


\section{Право и социальнье отночиения}

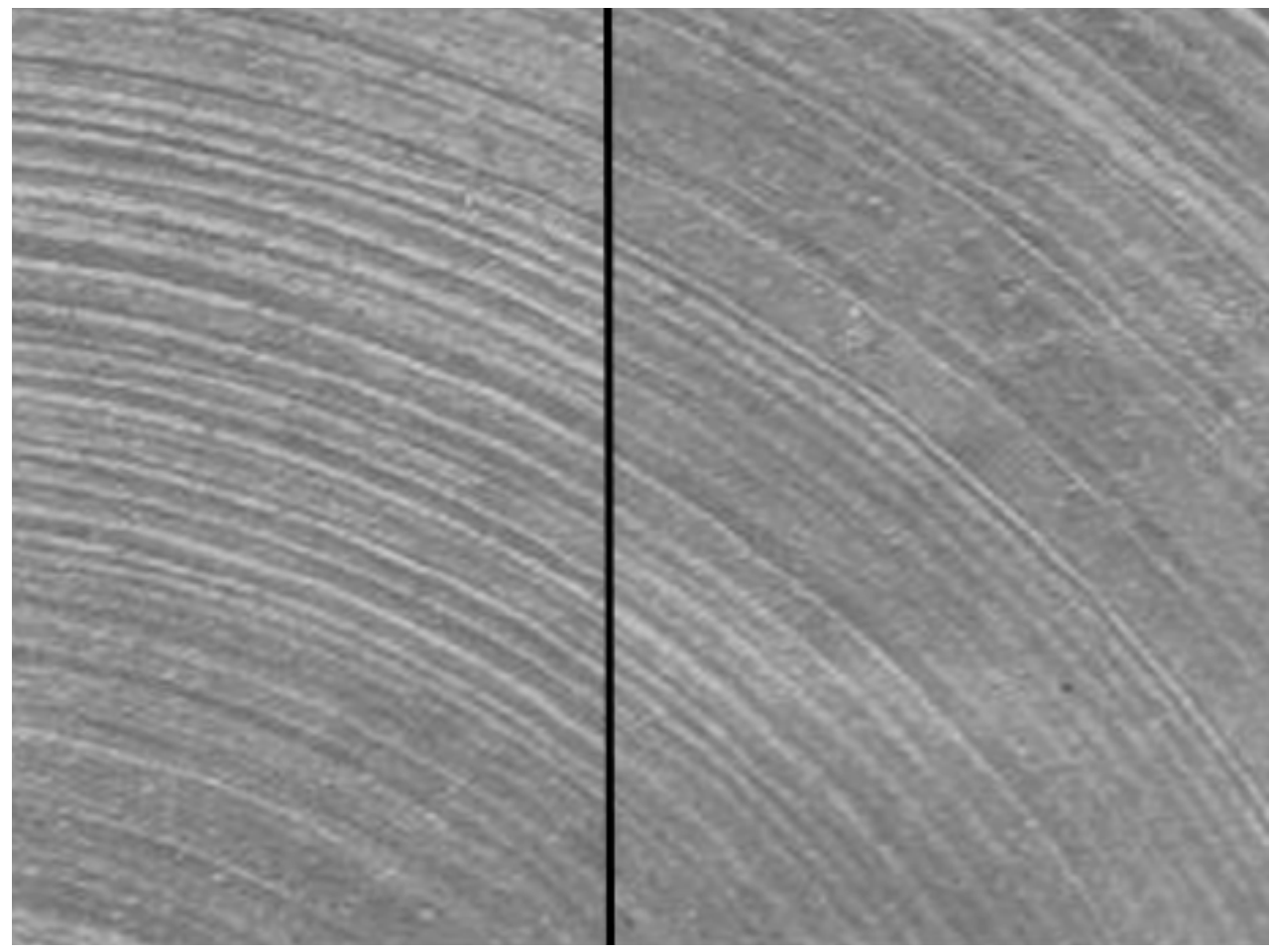

Рис. 1. Совмещение следов металлорежущего инструмента на поверхностях затворов двух разных пистолетов Ruger

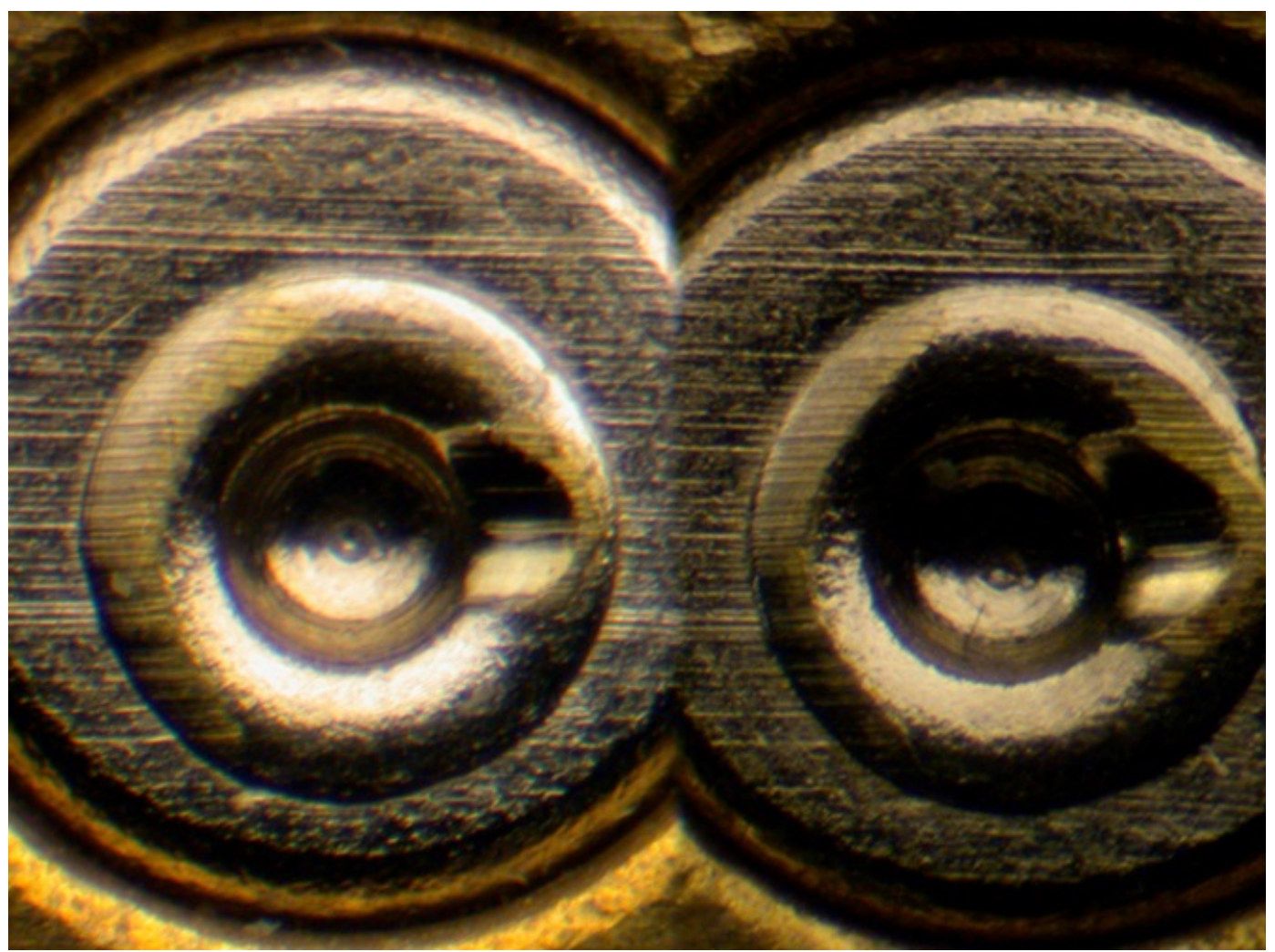

Рис. 2. Совмещение микрорельефа следов от станочного оборудования при изготовлении капсюлей 


\section{Социалъно-экономический и гуманитарный журнал Красноярского ГАУ. 2019. №4}

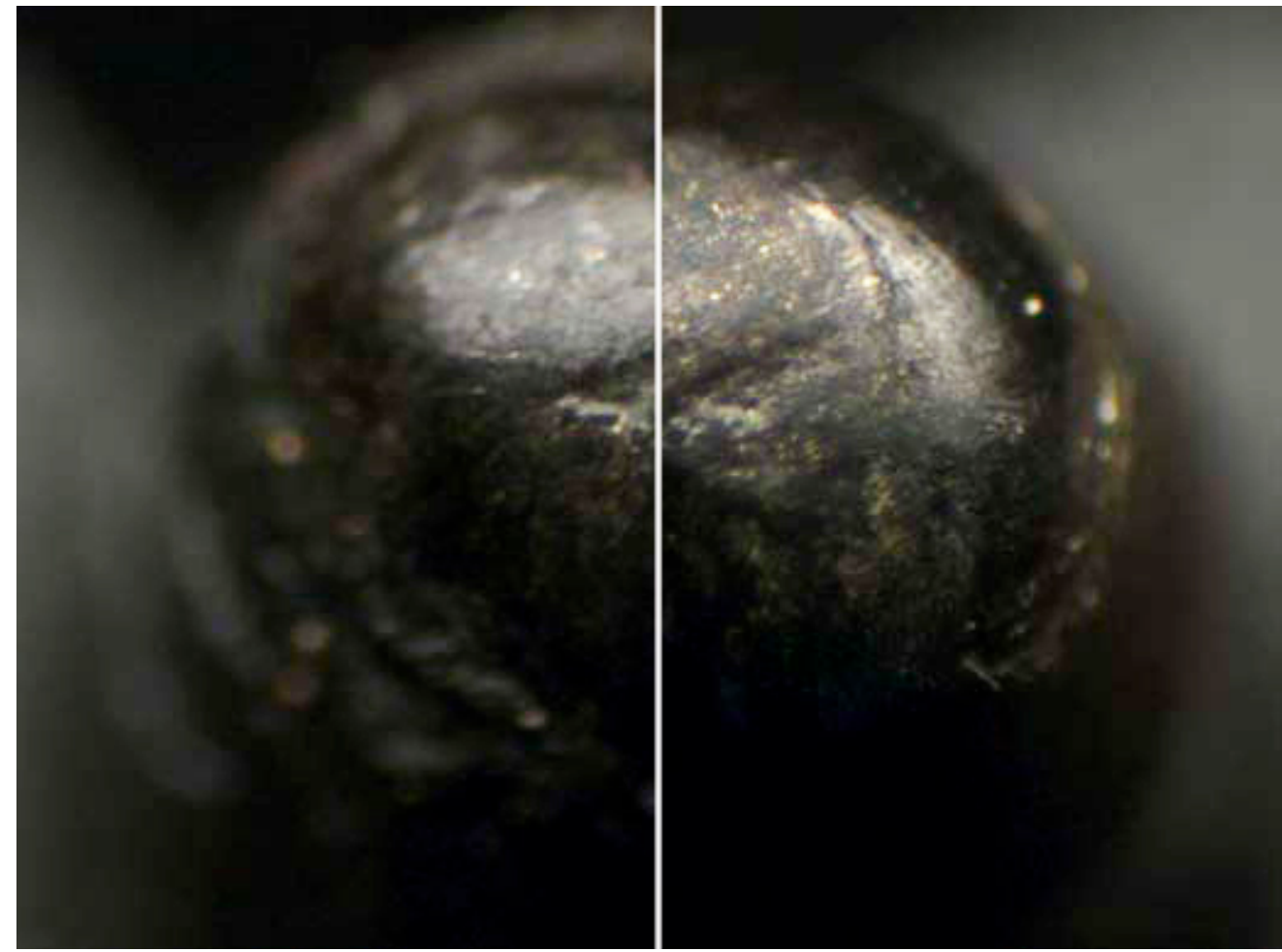

Pис. 3. Сопоставление бойков двух пистолетов Smith \& Wesson модели Sigma калибра 40 S\&W (ударники этих пистолетов изготовлены методом литья)

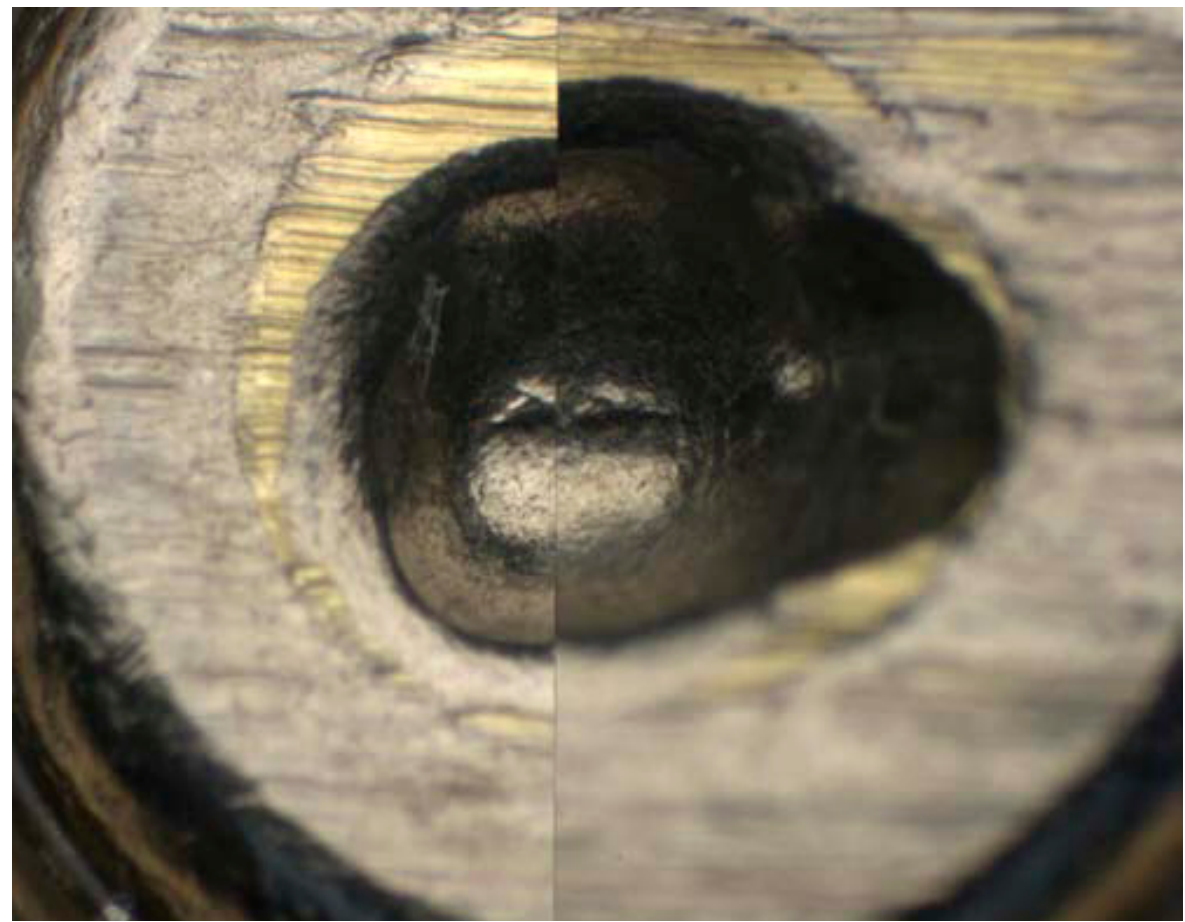

Puс. 4. Сопоставление микрорельефа следов бойков пистолетов Smith \&Wesson модели Sigma калибра $40 \mathrm{~S} \& W$ на капсюлях гильз 
Помимо этого, для криминалистических целей могут использоваться особенности производственных процессов, которые проявляются в особых следах (отметках), повторяющихся на деталях разных экземпляров оружия.

Например, при последовательном изготовлении деталей одним металлорежущим инструментом на современном станке с числовым программным управлением (ЧПУ) при одинаковых режимах резания имеют место практически идентичные вибрации инструмента. Помимо этого, станки с ЧПУ воспроизводят с высокой точностью движение инструмента и режимы обработки. Все это обеспечивает отображение дефектов его режущей кромки на нескольких обработанных деталях, вплоть до смены инструмента или его заточки. Соответственно эти особенности выражаются в повторяющихся признаках в следах на поверхностях готовых деталей.

Вследствие этого признаки высокоточного станочного оборудования могут быть приняты за частные признаки следообразующих частей оружия, и поэтому существует потенциальная опасность формулирования ошибочных выводов о тождестве.

В целях повышения объективности исследования огнестрельного оружия и его следов на пулях и гильзах при оценке следов и признаков всех видов важно обладать знаниями о производственных процессах; понимать причины образования различных дефектов на поверхностях инструментов, иметь представления о механизме образования следов инструментов на обрабатываемых поверхностях, уметь дифференцировать следы, характерные для обрабатывающего оборудования и следы случайного происхождения, возникшие вследствие износа или ремонта, учитывать весь комплекс признаков при принятии решений о наличии (отсутствии) тождества.

При идентификации оружия по выстреленным пулям, без наличия в распоряжении эксперта непосредственно ствола отождествляемого оружия, могут возникнуть экспертные ошибки вследствие того, что данные стволы могли быть изготовлены из одного ствола (т. е. являться его частями). Подобные прецеденты зафиксированы в практике работы ЭКЦ ГУ МВД России по г. Санкт-Петербургу и Ленинградской области. В этом случае части ствола в течение определенного периода будут иметь одинаковые идентификационные признаки, что может повлечь неверные экспертные выводы. В связи с этим при наличии признаков самодельного изготовления ствола, а также признаков его переделки, разделения (изменения длины), следует учитывать данные факторы при оценке совпадающих и различающихся признаков.

Следует иметь в виду, что при идентификации оружия по следам на пулях используются в основном методы совмещения динамических следов (трасс), которые имеют невысокую идентификационную значимость.

Вследствие этого при сравнении следов на пулях, выстреленных из разных образцов оружия, а также при сравнении различных изображе- 


\section{Социально-экономический и әуманитарный журнал Красноярского ГАУ. 2019. № 4}

ний при разных увеличениях на сравнительных микроскопах, эксперт может зафиксировать ложные совпадения и прийти к неверным выводам относительно тождества. В связи с этим при оценке совпадений необходимо учитывать весь комплекс признаков, в том числе и групповые признаки, характеризующие количество, направление, угол наклона и ширину полей нарезов, калибр, степень изношенности канала ствола и т. д.

Таким образом, в целях исключения возможных наиболее распространенных причин, которые могут привести к ошибочным выводам при производстве идентификационных экспертиз и исследований, необходимо выполнять следующие рекомендации:

- руководствоваться в своей деятельности не только ведомственными документами, но и положениями законодательства об оружии, а также материалами Пленумов Верховного суда с учетом всех последних изменений;

- применять методики исследования, соответствующие решаемым задачам, строго соблюдать все этапы исследования объектов и их последовательность;

- проводить раздельное исследование объектов в полном объеме;

- осуществлять подборку патронов для получения экспериментальных следов на пулях и гильзах, максимально близких к исследуемым как по материалам изготовления, так и по времени изготовления, стране, заводу (фирме-изготовителю);

- определять устойчивость всех выявленных признаков, оценивать их индивидуальность и неповторимость в совокупности, объяснять причины различий (совпадений);

- учитывать особенности современных производственных процессов и причины образования различных дефектов на поверхностях инструментов;

- в полной мере применять технические приемы сравнительного исследования (совмещение, сопоставление, наложение);

- правильно использовать криминалистическую технику, приемы и условия сравнения объектов (одинаковое освещение, и один и тот же масштаб увеличения изображений исследуемых объектов, сравнение одноименных следов).

\section{Литература}

1. Комаринец Б.М. Криминалистическое отождествление огнестрельного оружия по стреляным гильзам. - М., 1955. - 385 с.

2. Методика установления принадлежности объекта к огнестрельному оружию / ГУ ЭКЦ МВД России. - М., 2000. - 12 с.

3. Об оружии: федер. закон от 13.12.1996 г. № 150-Ф3 // Собрание законодательства РФ. - 1996. - № 51. - Ст. 5681. 
4. О государственной судебно-экспертной деятельности в Российской Федерации: федер. закон от 31.05.2001 № 73-ФЗ (ред. от 26.07.2019) // Собрание законодательства РФ. - 2001. - № 23. - Ст. 2291.

5. Об утверждении Наставления по организации экспертнокриминалистической деятельности в системе МВД России: приказ МВД России от 11.01.2009 № 7 (с изм. от 16.08.2018). - URL: https://xn--blaew.xn--p1ai/ mvd/structure1/Centri/J Ekspertno_kriminalisticheskij_centr/Osnovnie_normativno_pravovie_akti.

6. О судебной практике по делам о хищении, вымогательстве и незаконном обороте оружия, боеприпасов, взрывчатых веществ и взрывных устройств: постановление Пленума Верховного Суда РФ от 12.03.2002 г. № 5 (ред. от 11.06.2019) // Бюл. Верховного Суда РФ. 2002. - № 5.

7. Белкин Р.С. Курс криминалистики. - 3-е изд., доп. - М., 2001.

8. Судебная экспертиза: типичные ошибки / Е.И. Галяшина, В.В. Голикова, Е.Н. Дмитриев [и др.]; под ред. Е.Р. Россинской. - М.: Проспект, 2012. - 301с.

\section{Literatura}

1. Komarinec B.M. Kriminalisticheskoe otozhdestvlenie ognestrel'nogo oruzhija po streljanym gil'zam. - M., 1955. - $385 \mathrm{~s}$.

2. Metodika ustanovlenija prinadlezhnosti ob'ekta k ognestrel'nomu oruzhiju / GU J eKC MVD Rossii. - M., 2000. - 12 s.

3. Ob oruzhii: feder. zakon ot 13.12.1996 g. № 150-FZ // Sobranie zakonodatel'stva RF. - 1996. - № 51. - St. 5681.

4. O gosudarstvennoj sudebno-jekspertnoj dejatel'nosti v Rossijskoj Federacii: feder. zakon ot 31.05.2001 № 73-FZ (red. ot 26.07.2019) // Sobranie zakonodatel'stva RF. - 2001. - № 23. - St. 2291.

5. Ob utverzhdenii Nastavlenija po organizacii jekspertno-kriminalisticheskoj dejatel'nosti v sisteme MVD Rossii: prikaz MVD Rossii ot 11.01.2009 № 7 (s izm. ot 16.08.2018). - URL: https://xn--blaew.xn-plai/mvd/structure1/Centri/J Ekspertno_kriminalisticheskij_centr/Osno vnie_normativno pravovie_akti).

6. O südebnoj praktike po delam o hishhenii, vymogatel'stve i nezakonnom oborote oruzhija, boepripasov, vzryvchatyh veshhestv i vzryvnyh ustrojstv: postanovlenie Plenuma Verhovnogo Suda RF ot 12.03.2002 g. № 5 (red. ot 11.06.2019) // Bjul. Verhovnogo Suda RF. - 2002. - № 5.

7. Belkin R.S. Kurs kriminalistiki. - 3-e izd., dop. - M., 2001.

8. Sudebnaja jekspertiza: tipichnye oshibki / E.I. Galjashina, V.V. Golikova, E.N. Dmitriev [i dr.]; pod red. E.R. Rossinskoj. - M.: Prospekt, 2012. 301s.

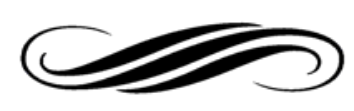

